\title{
Effect of pregnancy induced hypertension on maternal and perinatal outcome at tertiary care center in Ahmedabad, Gujarat, India
}

\author{
Meghavini R. Parmar, Pradhyuman Vaja*
} Department of Obstetrics and Gynecology, GMERS Medical College, ESIC Hospital, Bapunagar, Ahmedabad,
Gujarat, India

Received: 01 August 2017

Accepted: 01 September 2017

\section{*Correspondence:}

Dr. Pradhyuman Vaja,

E-mail: pshiladaria@gmail.com

Copyright: (c) the author(s), publisher and licensee Medip Academy. This is an open-access article distributed under the terms of the Creative Commons Attribution Non-Commercial License, which permits unrestricted non-commercial use, distribution, and reproduction in any medium, provided the original work is properly cited.

\begin{abstract}
Background: Pregnancy is a physiological event for utmost women. Almost $20 \%-30 \%$ of the adult population and more than 5\% - 8\% of all pregnancies in the world suffered from hypertension (HTN) and 5\% - 22\% of all pregnancies have develop some kind of medical problem due to hypertensive. To study the prevalence of PIH and to find out the association of PIH with perinatal and maternal outcome.

Methods: Prospective study was done among 110 cases of PIH admitted at department of obstetrics and Gynecology in B.J. Medical college, Ahmedabad during July 2005 to July 2007. Hypertension was identified based on the definition by the Australian Society of the Study of Hypertension in Pregnancy and that of the Working Group Report on High Blood Pressure in Pregnancy, which establish blood pressure levels > 140/90 $\mathrm{mmHg}$ or hypertension diagnosis marked on the record.

Results: Almost 44\% participants had mild PIH and 56\% had severe PIH. Almost 32\% participants had grade I changes and $29 \%$ had grade II changes. Low birth weight was found in 53\% baby. Maternal complication observed in $16 \%$ participants. Out of 16 patients, highest incidence of eclampsia was observed followed by APH, DIC respectively. One incidence of maternal death also occurred. Perinatal complications were observed in $46 \%$ cases which include IUGR (60.9\%), birth asphyxia (8.7\%), RDS (4.3\%) and perinatal death (15.2\%) respectively.

Conclusions: Pregnancy-induced hypertension is associated with multiple complications in the mother and baby, and particularly preterm delivery. Timely intervention of regular ANC check-up, nutrition, health education etc. can reduce the severity of PIH which lead to decrease in maternal and perinatal complications.
\end{abstract}

Keywords: ANC care, Eclampsia, Maternal complication, Pregnancy induced hypertension, Preeclampsia, Perinatal complication

\section{INTRODUCTION}

Pregnancy is a physiological event for utmost women. ${ }^{1}$ Almost $20 \%-30 \%$ of the adult population and more than $5 \%-8 \%$ of all pregnancies in the world suffered from hypertension (HTN) and 5\% - 22\% of all pregnancies have develop some kind of medical problem due to hypertensive. $^{2-6}$ Severe HTN raises maternal complications like the risk of heart attacks, cardiac failure, cerebro-vascular accidents and renal failure and neonatal complications like inappropriate placental oxygen transfer, Intra-uterine growth retardation (IUGR), premature delivery, placental abruption, stillbirth, and neonatal death. ${ }^{2}$ Pregnancy-induced hypertension $(\mathrm{PIH})$ is become a one of the major public health issue..$^{7-8}$

Pregnancy-induced hypertension (PIH) is classified as 1) Pregnancy-induced hypertension (without proteinuria), 2) 
Pre-eclampsia (with proteinuria), 3) Eclampsia (preeclampsia with convulsions), 4) Gestational hypertension (transient hypertension of pregnancy or chronic hypertension identified in the latter half of pregnancy). ${ }^{9}$

Treating the hypertension does not modify the progression of disease. In spite of, early diagnosis and treatment of PIH decreases not only the incidence of hypertensive crisis, but also the rate of neonatal complications. Present study was conducted with objectives to study the prevalence of PIH and to find out the association of PIH with perinatal and maternal outcome.

\section{METHODS}

This prospective study was done among 110 cases of PIH admitted at department of obstetrics and Gynecology in B. J. Medical college, Ahmedabad during July 2005 to July 2007. Data collection was done after ethical permission from institutional ethical committee and informed consent of clients. Inclusion criteria for present study was all pregnant women $\geq 28$ week of pregnancy irrespective of age and parity. Pre-tested questionnaire was administered and details like socio-demographic information, past history of medical illness, menstrual history was collected.

Hypertension was identified based on the definition by the Australian Society of the Study of Hypertension in Pregnancy and that of the Working Group Report on High Blood Pressure in Pregnancy, which establish blood pressure levels $>140 / 90 \mathrm{mmHg}$ or hypertension diagnosis marked on the record. ${ }^{8,10}$ The data were recorded in an Excel sheet and descriptive analysis was performed, of which data are presented in the tables.

\section{RESULTS}

A Table 1 show that $51 \%$ participants belonged to 21 to 25 years age group and mean age was 27.6 years with 5.6 SD. Mean gestational age was 36.5 week with 7.4 SD. Almost $46 \%$ participants had blood group ' $\mathrm{O}$ ' followed by $28 \%$ had ' $A$ ' and $22 \%$ had 'B'. Almost $67 \%$ participants had done ANC visit in routine visit and among them $64 \%$ were belonged in primigravida group. Around $67 \%$ delivery was done through vaginal route and $16 \%$ through instrumental (forceps and vacuum).

Figure 1 shows that $44 \%$ participants had mild PIH and $56 \%$ had severe PIH. Incidence of PIH was $6.1 \%$ (100/1639). Figure 2 shows that severe anemia was present in $19 \%$ participants and very severe anemia in $4 \%$ participants.

Table 2 shows that edema was present in $59 \%$ participants followed by headache $(33 \%)$ and visual disturbance $(19 \%)$. Proteinuria was present in $78 \%$ participants. Adverse perinatal outcomes were increased with increased level of Proteinuria. Almost 36.36\% participants with mild PIH and $73.21 \%$ participants with severe PIH had retinal changes which were reversible. Almost 32\% participants had grade I changes and 29\% had grade II changes. Normal Doppler finding was observed in $54 \%$ participants. Present study observed APGAR score 0-3 in 4\% and 4-6 in 46\% participants at 1 min. Low birth weight was found in $53 \%$ baby.

Table 1: Socio-demographic information of participants $(\mathrm{N}=100)$.

\begin{tabular}{|c|c|}
\hline Variable & Number $(\%)$ \\
\hline \multicolumn{2}{|l|}{ Age (in years) } \\
\hline $18-20$ & 2 \\
\hline $21-25$ & 51 \\
\hline $26-30$ & 32 \\
\hline$>30$ & 15 \\
\hline Mean age \pm SD & $27.6 \pm 5.6$ \\
\hline \multicolumn{2}{|l|}{ Gestational age (in week) } \\
\hline $28-32$ & 23 \\
\hline $33-36$ & 34 \\
\hline $37-40$ & 42 \\
\hline$>40$ & 1 \\
\hline Mean Gestational age \pm SD & $36.5 \pm 7.4$ \\
\hline \multicolumn{2}{|l|}{ Blood group } \\
\hline $\mathrm{O}$ & 46 \\
\hline A & 28 \\
\hline B & 22 \\
\hline $\mathrm{AB}$ & 4 \\
\hline \multicolumn{2}{|l|}{ Gravidity } \\
\hline $1^{\text {st }}$ & 64 \\
\hline $2^{\text {nd }}$ & 15 \\
\hline $3^{\mathrm{rd}}$ & 8 \\
\hline $4^{\text {th }}$ & 5 \\
\hline $5^{\text {th }}$ & 3 \\
\hline $6^{\text {th }}$ & 5 \\
\hline \multicolumn{2}{|l|}{ Ante-natal visit } \\
\hline Booked & 67 \\
\hline Emergency & 33 \\
\hline \multicolumn{2}{|l|}{ Mode of delivery } \\
\hline Vaginal & 67 \\
\hline $\begin{array}{l}\text { Instrumental (forceps and } \\
\text { vacuum) }\end{array}$ & $\begin{array}{l}16 \text { ( } 3 \text { forceps }+13 \\
\text { vaccume) }\end{array}$ \\
\hline Caesarean Section & 17 \\
\hline
\end{tabular}

SD - Standard Deviation

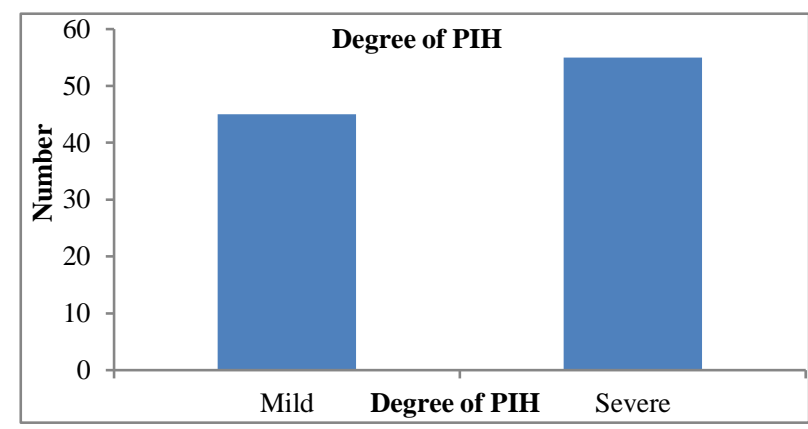

Figure 1: Degree of PIH among participants ( $\mathrm{N}=\mathbf{1 0 0 / 1 6 3 9 ) .}$ 
Table 2: Maternal and perinatal outcome among participants $(\mathrm{N}=100)$.

\begin{tabular}{|c|c|c|c|c|c|}
\hline Variable & \multicolumn{5}{|c|}{ Number } \\
\hline \multicolumn{6}{|l|}{ Maternal Morbidity } \\
\hline Headache & \multicolumn{5}{|l|}{33} \\
\hline Edema & \multicolumn{5}{|l|}{59} \\
\hline Visual disturbance & \multicolumn{5}{|l|}{19} \\
\hline Loss of fetal movement & \multicolumn{5}{|l|}{8} \\
\hline Epigestric pain & \multicolumn{5}{|l|}{2} \\
\hline Convulsion & \multicolumn{5}{|l|}{6} \\
\hline Proteinuria & Total & IUD $(n=6)$ & SB $(n=1)$ & Neaontal Death $(n=4)$ & Preterm Delivery $(n=57)$ \\
\hline Nil & 3 & 0 & 0 & 0 & 2 \\
\hline Trace & 10 & 0 & 0 & 0 & 8 \\
\hline+1 & 18 & 1 & 0 & 0 & 9 \\
\hline+2 & 28 & 1 & 1 & 1 & 14 \\
\hline+3 & 32 & 3 & 0 & 1 & 18 \\
\hline+4 & 9 & 2 & 0 & 2 & 6 \\
\hline Fundoscopy (in Grade) & Mild I & $H(n=44)$ & & Seve & IH $(n=56)$ \\
\hline I & 11 & & & 5 & \\
\hline II & 5 & & & 16 & \\
\hline III & 0 & & & 15 & \\
\hline IV & 0 & & & 5 & \\
\hline \multicolumn{6}{|c|}{ Gestational Age at onset of labour } \\
\hline Pre-term & \multicolumn{5}{|c|}{57} \\
\hline Full-term & \multicolumn{5}{|l|}{42} \\
\hline Post-term & \multicolumn{5}{|l|}{1} \\
\hline \multicolumn{6}{|l|}{ Placental Grading } \\
\hline 0 & \multicolumn{5}{|l|}{8} \\
\hline I & \multicolumn{5}{|l|}{32} \\
\hline II & \multicolumn{5}{|l|}{29} \\
\hline III & \multicolumn{5}{|l|}{31} \\
\hline \multicolumn{6}{|c|}{ Biophysical Profile Score } \\
\hline $0-2$ & 0 & & & & \\
\hline 4 & 1 & & & & \\
\hline 6 & 7 & & & & \\
\hline $8-10$ & 86 & & & & \\
\hline Doppler Finding & & & & & \\
\hline Normal & 54 & & & & \\
\hline Abnormal & 46 & & & & \\
\hline APGAR Score $(n=93)$ & & & & & \\
\hline At 1 Min & & & & & \\
\hline $0-3$ & 4 & & & & \\
\hline $4-6$ & 46 & & & & \\
\hline $7-10$ & 43 & & & & \\
\hline At 5 min & & & & & \\
\hline $0-3$ & 0 & & & & \\
\hline $4-6$ & 11 & & & & \\
\hline $7-10$ & 82 & & & & \\
\hline Birth Weight (in Kg) & & & & & \\
\hline$<2.5$ & 53 & & & & \\
\hline $2.5-3$ & 40 & & & & \\
\hline$>3$ & 7 & & & & \\
\hline Blood Pressure on follov & & & & & \\
\hline Normal & 87 & & & & \\
\hline High & 12 & & & & \\
\hline Proteinuria on follow-u & & & & & \\
\hline Absent & 95 & & & & \\
\hline Present & 4 & & & & \\
\hline
\end{tabular}




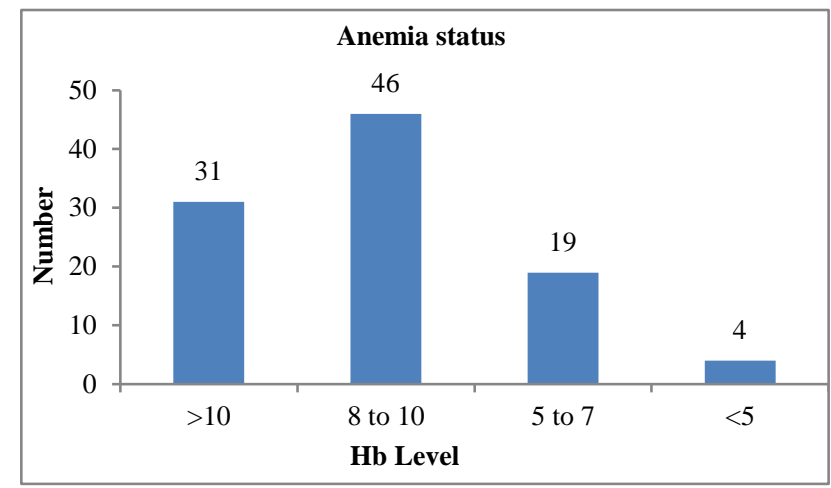

Figure 2: Anemia status of participants $(\mathrm{N}=100)$.

Figure 3 shows that maternal complication observed in $16 \%$ participants. Out of 16 patients, highest incidence of eclampsia was observed followed by APH, DIC respectively. One incidence of maternal death also occurred. Perinatal complications were observed in $46 \%$ cases which include IUGR $(60.9 \%)$, birth asphyxia $(8.7 \%)$, RDS (4.3\%) and perinatal death (15.2\%) respectively.

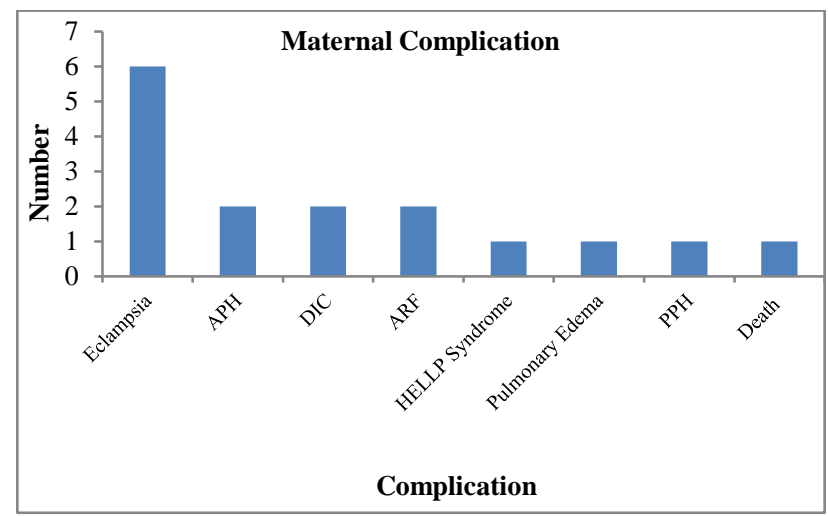

APH - Ante-partum heamorrhage, DIC - Disseminated Intravascular coagulation, ARF - Acute renal failure, PPH Post-partum heamorrhage

Figure 3: Maternal complication among study participants $(\mathrm{N}=16)$.

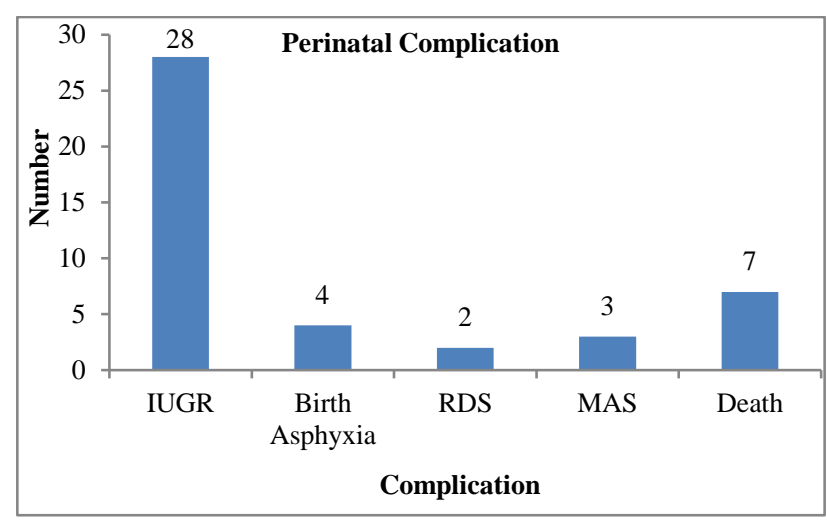

RDS - Respiratory distress syndrome, MAS - Muconium Aspiration syndrome.

Figure 4: Perinatal complications among study participants $(\mathrm{N}=46)$.

\section{DISCUSSION}

In present study, incidence of PIH was observed in $6.1 \%$ cases (100/1639). This finding is lower than the similar study done by Chaim SRP et al, Cunningham FG et al, Oliveira $\mathrm{CA}$ et al and Rose $\mathrm{J}$ et al.,10-12 Factors like Awareness among women regarding ANC care, less incidence of teenage pregnancy responsible for the low incidence of PIH. Present study observed $1 / 3^{\text {rd }}$ emergency cases which is comparable with the similar study done by Sivkumar $\mathrm{S}$ et al and Gadappa $\mathrm{S}$ et al. ${ }^{13,14}$ Low incidence of emergency cases is due to awareness and counseling of the pregnant women. Present study observed PIH was more common in Primigravida cases and It is due to several factors like teenage pregnancy, early marriage, illiteracy, social ignorance and ritual and lack of family planning adaptation. This finding is correlated with the similar study done by Rose $\mathbf{J}$ et al and Dekker and Sibai et al. ${ }^{12,15}$. Mean age of participants was 27.6 years which is comparable with similar study done by Rose $\mathrm{J}$ et al. ${ }^{12}$ Mean age of gestational age was 36 week which quite similar with the study done by Rose $\mathrm{J}$ et al. ${ }^{12}$ Present study also observed higher incidence of PIH among preterm delivery. Preterm delivery was due to early spontaneous labour or because of therapeutic induction necessitated by severe PIH. In present study, out of 57 preterm delivery 6 patients had induction done die to IUD, 3 patients had induction done due to severe PIH and remaining 48 patients had gone in spontaneous labour.

In our study, normal hemoglobin level found in only $31 \%$ cases and anemia is responsible for high incidence of preterm delivery and low birth weight babies which leads to increase incidence of perinatal morbidity and mortality. Present study observed incidence of convulsion in 6 cases which is lower than the similar study done by Sivakumar $\mathrm{S}$ et al. ${ }^{13}$ Events of convulsion can be decrease by regular ANC care. Present study observed poor perinatal outcome in patients with $\geq+2$ proteinuria. Present study found that incidence of severe PIH is was increased with rise in the retinal change in fundoscopy grade. LSCS incidence in present study found among $17 \%$ cases and the indication for it were severe $\mathrm{PIH}$, foetal distress, precious pregnancy, non-progress labour etc. Higher incidence of LSCS was found in similar study done by Sivakumar $\mathrm{S}$ et al. ${ }^{13}$

Eclampsia was the most common complication in present study which was followed by APH, DIC, ARF etc which is quite comparable with the similar study done by Bansal $\mathrm{V}$ et al. ${ }^{16}$ One maternal death was occurred in present study which is quite lower than the similar study done by Rose J et al and Shrinivas et al. ${ }^{12}$ In our study, only $42 \%$ patients had term delivery and $57 \%$ had preterm delivery. Association was preterm delivery with PIH is well known fact.

Nutrition of the pregnant women is an important factor in foetal development. In our study, low birth weight incidence was observed in 53\% cases. Low APGAR 
score $(<7)$ in present study found in $53.8 \%$ cases (at 1 $\min$ ) and $11.8 \%$ cases (at $5 \mathrm{~min}$ ) which is higher than the similar study done by Khosravi $\mathrm{S}$ et al and Chaim SRP et al. ${ }^{17,1}$ Present study was found higher perinatal mortality and morbidity with increase in placental maturity.

\section{CONCLUSION}

Pregnancy-induced hypertension is associated with multiple complications in the mother and baby, and particularly preterm delivery. Complications such as HELLP syndrome can sometimes prove fatal to mother and fetus. In our study, incidence of PIH was found to be more in Primigravida, age group of 21-25 years and gestational age. Timely intervention of regular ANC check-up, nutrition, health education etc. can reduce the severity of PIH which lead to decrease in maternal and perinatal complications.

Funding: No funding sources Conflict of interest: None declared

Ethical approval: The study was approved by the Institutional Ethics Committee

\section{REFERENCES}

1. Chaim SRP, Oliveira SMJ, Kimura AF. Pregnancyinduced hypertension and the neonatal outcome. Acta Paul Enferm. 2008;21(1):53-8.

2. Cherney D, Nathan AH, Laufer LN, Roman AS. Hypertension in Pregnancy. Current Diagnosis and Treatment: Obstetr Gynecol. 11 ${ }^{\text {th }}$ Edition, Chapter 26; 2012.

3. Cunnigham FG, Leveno K, Bloom S. (2010) Willams Obstetrics. 23 ${ }^{\text {rd }}$ Edition, McGraw-Hill, Medical Publishing Division, New York; 2010.

4. Vest AR and Cho LS. Hypertension in Pregnancy. Cardiology Clinics. 2012;30:407-423.

5. Wagner SJ, Barac S. and Garovic VD. (2007) Hypertensive Pregnancy Disorders: Current Concepts. Journal of Clinical Hypertension. 2017;9: 560-6.

6. Henry CS, Biedermann SA, Campbell MF. and Guntupalli, J.S. Spectrum of hypertensive emergencies in pregnancy. Critical Care Clinics. 2004;20:697-712.

7. Chen XK, Wen SW, Smith G, Yang Q, Walker M. Pregnancy-induced hypertension is associated with lower infant mortality in preterm singletons. BJOG. 2006;113(5):544-51.

8. Brown MA, Hague WM, Higgins J, Lowe S, McCowan L, Oats J, et al. Austalasian Society of the Study of Hypertension in Pregnancy. The detection, investigation and management of hypertension in pregnancy: full consensus statement. Aust N Z J Obstet Gynecol. 2000;40(2):139-55.

9. Ching-Ming Liu, Po-jen Cheng, Sheuenn-Dyh Chang. Maternal Complications and Perinatal Outcomes associated with Gestational Hypertension and Severe Preeclamsia in Taiwanese Women. J Formes Medic Associat. 2008;107(2):129-38.

10. Working Group Report on High Blood Pressure in Pregnancy. National High Blood Pressure Education Program. Bethesda (MD): National Institutes of Health; 2000. (NIH Publication No.00-3029).

11. Oliveira CA, Lins CP, Sá RA, Netto HC, Bornia RG, Silva NR, Amim Junior J. Síndromes hipertensivas da gestação e repercussões perinatais. Rev. bras. saúde matern. infant. 2006;6(1):93-8.

12. Jophy R, Thomas A, Jairaj P. J obstet and gynae of India. 2002;52(5):26-9.

13. Sivakumar S, Bhat BV, Badhe BA. Effect of pregnancy induced hypertension on mothers and their babies. The Ind J Pediatr. 2007;74(7):623-5.

14. Gadapaa S. Critical care and obstetric management in eclampsia in a teaching hospital, Abstract, free communication paper, $42^{\text {nd }}$ all India congress of obstetric and gynecology; 1998.

15. Sibai B, Dekker G, Kupferminc M. Pre-eclampsia. The Lancet. 2005;365(9461):785-99.

16. Bansal D, Deodhar P. A clinical study of maternal and perinatal outcome in oligohydramnios. J Res Med Den Sci. 2015;3(4):312-6.

17. Khosravi S1, Dabiran S, Lotfl M, Asnavandy M. Study of the Prevalence of Hypertension and Complications of Hypertensive Disorders in Pregnancy. Open J Preventive Medic. 2014;4:860-7.

Cite this article as: Parmar MR, Vaja P. Effect of pregnancy induced hypertension on maternal and perinatal outcome at tertiary care center in Ahmedabad, Gujarat, India. Int J Reprod Contracept Obstet Gynecol 2017;6:4661-5. 